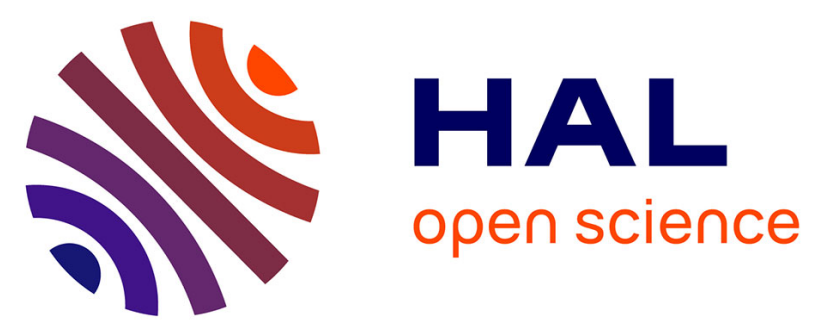

\title{
Associations of multiple occupational exposures with major depressive and generalized anxiety disorders: findings from the French national Working Conditions survey
}

Sandrine Bertrais, Amélie Mauroux, Jean-François Chastang, Isabelle

Niedhammer

\section{To cite this version:}

Sandrine Bertrais, Amélie Mauroux, Jean-François Chastang, Isabelle Niedhammer. Associations of multiple occupational exposures with major depressive and generalized anxiety disorders: findings from the French national Working Conditions survey. Depression and Anxiety, 2021, 38 (3), pp.337350. 10.1002/da.23111 . hal-02976037

\section{HAL Id: hal-02976037 \\ https://univ-angers.hal.science/hal-02976037}

Submitted on 23 Nov 2020

HAL is a multi-disciplinary open access archive for the deposit and dissemination of scientific research documents, whether they are published or not. The documents may come from teaching and research institutions in France or abroad, or from public or private research centers.
L'archive ouverte pluridisciplinaire HAL, est destinée au dépôt et à la diffusion de documents scientifiques de niveau recherche, publiés ou non, émanant des établissements d'enseignement et de recherche français ou étrangers, des laboratoires publics ou privés. 
Associations of multiple occupational exposures with major depressive and generalized anxiety disorders: findings from the French national Working

\section{Conditions survey}

Running title: Working conditions, depression and anxiety

Sandrine Bertrais ${ }^{1}$ | Amélie Mauroux ${ }^{2}$ | Jean-François Chastang ${ }^{1}$ | Isabelle Niedhammer ${ }^{1}$

1 INSERM, Univ Angers, Univ Rennes, EHESP, Irset (Institut de recherche en santé, environnement et travail) - UMR_S 1085, ESTER Team, Angers, France

${ }^{2}$ DARES, Ministère du Travail, Paris, France

\section{Correspondence:}

Sandrine Bertrais

INSERM UMR 1085 - IRSET, Equipe Epidémiologie en Santé au Travail et Ergonomie (ESTER)

Faculté de Santé - Département Médecine

28 rue Roger Amsler, CS 74521

F-49045 Angers Cedex 1

France

Email: sandrine.bertrais@univ-angers.fr 


\section{ACKNOWLEDGEMENTS}

The authors thank the members of the DARES (French ministry of labour) and all the participants to the 2016 Working Conditions survey, who made this study possible.

\section{CONFLICT OF INTERESTS}

The study was supported by DARES of the French ministry of labour (grant number: 2018/037) awarded to Isabelle Niedhammer. The other authors have no conflict of interests to declare. 


\section{ABSTRACT}

Background: There have been numerous studies on the associations between psychosocial work factors and mental health, but very few of them explored the cumulative effects of these factors. The objectives were to study the associations between multiple occupational exposures and two common mental disorders, major depressive episode (MDE) and generalized anxiety disorder (GAD), among employees in France.

Methods: The data came from the 2016 French national Working Conditions Survey based on a representative sample of 20,430 employees ( 8,579 men, 11,851 women) aged 15 to 65 years. MDE and GAD were assessed using the MINI standardized diagnostic interview. Occupational exposures included 21 psychosocial work factors grouped into 5 dimensions, 4 factors related to working time/hours and 4 physical work exposures. Logistic regression modeling for weighted data was performed to evaluate the associations of occupational exposures with MDE and GAD in men and women separately.

Results: The prevalence of MDE and GAD was higher among women $(8.6 \%$ and $8.7 \%$ respectively) than among men (4.3\% and $4.6 \%)$. Most psychosocial work factors were associated with MDE and/or GAD. A linear increase in the risk of MDE/GAD with the number of psychosocial work factors was found for each dimension, except workplace violence. The risk of MDE also increased linearly with multiple physical work exposures. Conclusions: Our results showed that a wide variety of occupational exposures were associated with clinical depression and anxiety, and that the risk of disease increased with multiple exposures to psychosocial and physical factors at work.

KEYWORDS: working conditions, occupational exposures, psychosocial work factors, multiple exposures, anxiety, depression 


\section{1 | INTRODUCTION}

Depression and anxiety are the two most prevalent mental disorders and are major contributors to the high costs of common mental disorders (EU-OSHA, 2014; World Health Organization, 2017). In addition to the deterioration of health and quality of life, these disorders have costly consequences for the working age population, inducing lower work performance, sickness absence, disability/unemployment, and early retirement (Birnbaum et al., 2010; Knudsen, Harvey, Mykletun, \& Øverland, 2013; Wedegaertner et al., 2013).

There is a large literature on the associations between psychosocial work factors and mental health, and several systematic reviews were published including a meta-review (Harvey et al., 2017). However, a large majority of the studies explored mental health symptoms, and far fewer studies focused on clinically diagnosed depression and anxiety. Only one systematic review and meta-analysis of data from published and unpublished studies concluded that job strain (i.e. low decision latitude and high psychological demands) was associated with an increased risk of clinical depression (Madsen et al., 2017). Other psychosocial work exposures may play a role in mental disorders: low social support, effortreward imbalance, workplace violence or bullying, role stressors (i.e. role ambiguity and conflict), organizational injustice, organizational changes, and job insecurity (Kim \& von dem Knesebeck, 2016; Netterstrøm et al., 2008; Nieuwenhuijsen, Bruinvels, \& Frings-Dresen, 2010; Rönnblad et al., 2019; Rugulies, Aust, \& Madsen, 2017; Schmidt, Roesler, Kusserow, \& Rau, 2014; S. Stansfeld \& Candy, 2006; Theorell et al., 2015; Verkuil, Atasayi, \& Molendijk, 2015). However, studies evaluating the associations of these factors with clinical depression remain seldom and for anxiety, they are even rarer.

In addition, most previous studies examined psychosocial work factors, and other occupational exposures such as those related to working hours/time and the physical work 
environment were often not considered. The effects of atypical working hours on common mental health problems remain inconclusive according to the meta-review by Harvey et al. (Harvey et al., 2017). A meta-analysis demonstrated that shift work increased the risk for poor mental health, particularly depressive symptoms in women (Torquati, Mielke, Brown, Burton, \& Kolbe-Alexander, 2019). Night shift work was found to be associated with an increased risk of depression/depressive symptoms in another meta-analysis (Lee et al., 2017). In a meta-analysis based on previous studies and unpublished data, it was suggested that the association of long working hours with depressive symptoms may differ according to country, being strong in Asian countries, weaker in Europe and not significant in North America or Australia, because of differences in cultural and occupational health policy (Virtanen et al., 2018). However, the effects of overtime work on depressive disorders clinically diagnosed or assessed by a structured interview remained inconclusive in another review and meta-analysis (Watanabe, Imamura, \& Kawakami, 2016). Finally, there is very little knowledge on the impact of physical work environment on the risk of depression and anxiety (Theorell et al., 2015). Another important limitation of the literature is that most studies explored a limited number of occupational exposures, and did not assess the effects of multiple exposures.

The objectives of this study in a large nationally representative sample of French workers were therefore to examine the associations of a wide variety of occupational exposures, including psychosocial work factors, factors related to working time/hours and physical work exposures, with major depressive episode (MDE) and generalized anxiety disorder (GAD), measured using a standardized diagnostic interview. We additionally assessed whether there were cumulative effects of occupational exposures on these two outcomes. 


\section{2 | METHODS}

\section{1 | Study sample}

This cross-sectional study relied on the data from the national periodic survey on working conditions conducted by the French Ministry of Labour (DARES), the Working Conditions survey, that focused on psychosocial work factors in 2016. The data were collected on a nationally representative sample of the French working population aged 15 or more. Workers were selected through a two-stage random sampling process: firstly at the household level using national population and housing census data, and secondly at the individual level in households where there was more than one worker. Data collection was performed through a face-to-face interview at respondent's home followed by a selfadministered questionnaire. The survey received approval from the French ethics committees (CNIL no 2015-079 and CNIS no 2015X073TV).

\section{$2.2 \mid$ Measures}

\subsection{1 | Mental disorders}

MDE within the last two weeks and GAD within the last 6 months were assessed using the corresponding modules and diagnostic algorithms of the 5.0.0 version of the Mini International Neuropsychiatric Interview (MINI), which has been shown as a reliable diagnostic interview for the diagnosis of common mental disorders defined with the clinical criteria from the Diagnostic and Statistical Manual of Mental Disorders 4th edition (DSM-IV) (Lecrubier et al., 1997; D. Sheehan et al., 1997; D. V. Sheehan et al., 1998). 


\subsection{2 | Occupational factors}

A total of 79 items were used to construct 21 psychosocial work factors, following international concepts, such as those from COPSOQ (Kristensen, Hannerz, Høgh, \& Borg, 2005; Pejtersen, Kristensen, Borg, \& Bjorner, 2010). These factors were grouped as follows:

1. Demands at work: quantitative demands ( 7 items), cognitive demands (3 items), emotional demands ( 2 items), demands for hiding emotions ( 2 items)

2. Work organization and job content: influence at work (6 items), degree of freedom (3 items), possibilities for development (5 items), meaning of work (3 items)

3. Interpersonal relations and leadership: social support from supervisors and colleagues (7 items), sense of community ( 3 items), quality of leadership (5 items), predictability ( 2 items), role clarity ( 2 items), role conflict ( 9 items)

4. Work-individual interface: job satisfaction ( 3 items), work-family conflict (2 items), job insecurity (2 items), changes at work (2 items), temporary employment (1 item)

5. Workplace violence: internal violence at work (i.e. from colleagues, supervisors, etc.) (6 items), external violence at work (i.e. from the public, patients, clients, customers, etc.) (4 items)

The score of each factor was calculated by summing all items and was dichotomized at the median of the total sample to define low or high exposure groups. Multiple exposure was assessed by counting the number of factors to which the individual was exposed, firstly for each group of factors, and secondly for all groups together. Thus, the overall measure of psychosocial work exposure ranged from 0 to 21.

Four factors related to working time/hours were studied: long working hours (1 item: working more than 48 hours per week, following the European directive on working time), 
night work ( 1 item: working between midnight and 5 am at least 50 nights a year), shift work ( 1 item: working on alternating/rotating shifts), and unsocial work days ( 1 item: working on Saturday or Sunday at least 40 times a year).

Physical work exposures included four factors that were: biomechanical exposure ( 7 items: long-term exposure to standing, difficult or tiring position, walking, heavy loads, painful or tiring movements, vibrations, repetitive tasks), exposure to fumes or dust (1 item), exposure to toxic and dangerous products (1 item) and exposure to noise (1 item).

Two indexes of multiple exposure were also calculated for working time/hours and physical work exposures.

\subsection{3 | Covariates}

The covariates were the following: age, marital status (living with or without a partner), social support outside work ( 2 items: having someone to rely one to discuss personal issues or take a difficult decision, and need more help than help received), life events before the age of 18 (5 items), life events within the last 3 years (4 items), and employment characteristics including occupation and economic activity of the company.

These covariates were chosen because they were known to be risk factors for depressive and/or anxiety disorders (Gutiérrez-Rojas et al., 2020; Michael et al., 2007), or because they were the main variables characterizing occupational activity which are important variables to consider when studying the associations between occupational exposures and health outcomes among working populations.

\section{3 | Statistical analyses}


All analyses were performed using weighted data to take non-response and calibration into account, and to provide results that could be extrapolated to the whole French working population in 2016. Non-response was corrected both at household level and at individual level. The following calibration variables were used: gender, age, economic activity of the company, occupation and employment status.

Comparisons between genders were performed for all studied variables using the Rao-Scott chi-square test. Differences in the prevalence of MDE/GAD according to covariates were tested using the same test. Weighted logistic regression models were used to investigate the associations between each occupational factor and MDE/GAD. Odds-ratios adjusted for all covariates and $95 \%$ confidence intervals were calculated. Multiple exposures to occupational factors were also studied using weighted logistic regression models, and trend tests were performed to assess whether the risk of MDE/GAD increased with the number of exposures. These analyses were also adjusted for covariates.

Sensitivity analyses were performed: (1) for the study of the associations between each occupational factor and MDE/GAD, additional adjustment was performed for full/part time work, public/private sector, and company size, as these variables may be associated with occupational exposures and/or outcomes, (2) for the study of multiple exposure to psychosocial work factors, additional adjustment was done for working time/hours factors and physical work exposures, to control for the potentially confounding effects of these exposures, and (3) tertiles of the score for each occupational factor were studied instead of exposure dichotomized at the median, to assess dose-response associations.

Statistical analyses were performed among men and women separately using SAS version 9.4M5 (SAS Institute Inc., Cary, NC, USA). Gender differences in the associations of occupational factors with MDE/GAD were tested by including interaction terms. 


\section{3 | RESULTS}

\section{1 | Description of the study sample}

The overall rate of participation in the 2016 Working Conditions survey was $74.4 \%$. Among the 27,610 participants, there were 21,742 employees aged 15 to 65 years working at the time of the survey, and among them, 20,430 (94.0\%) responded to the self-administered questionnaire and constituted the study sample, i.e. 8,579 men and 11,851 women (see Table 1 for the description of the study sample according to covariates). Significant gender differences were observed for all covariates $(p \leq .006)$, except for age $(p=.073)$.

\section{2 | Prevalence of MDE and GAD}

Table 1 also shows that the prevalence of MDE and GAD was higher among women (8.6\% and $8.7 \%$ respectively) than among men ( $4.3 \%$ and $4.6 \%)$. There was no difference between age groups, but the prevalence increased with lower social support outside work and with the number of life events during childhood and within the last 3 years in both genders. A higher prevalence of MDE was observed in women living without a partner. MDE and GAD were more prevalent among female unskilled occupational groups. No significant difference in the prevalence of MDE and GAD was found according to economic activity of the company.

\subsection{Associations of each occupational factor with MDE/GAD}


Tables 2-3 present the associations between each occupational exposure and MDE/GAD before and after adjustment for covariates.

For both genders, most psychosocial work factors were associated with MDE and/or GAD. There was however no association of emotional demands, predictability and external violence in men, degree of freedom in women, and temporary employment in both genders with both MDE and GAD after adjustment for covariates.

No factors related to working time/hours were significantly associated with MDE or GAD, after adjustment for covariates. However, among women, unsocial work days were associated with MDE and a protective association was observed between shift work and MDE.

All physical work factors were associated with MDE, except toxic and dangerous products exposure in men, after adjustment for covariates. High biomechanical exposure and exposure to toxic and dangerous products were associated with GAD in women, while noise exposure was found to be associated with GAD in men.

Some significant gender differences in the exposure-outcome associations were observed: the strength of the associations of low job satisfaction and internal violence with MDE were stronger in men than in women, and the associations of role conflict and changes at work with GAD were significant for women but non-significant for men.

In the sensitivity analyses, the results remained unchanged after additional adjustment. Furthermore, when we analyzed occupational exposures using tertiles instead of dichotomized exposures, we found a large number of dose-response associations with MDE and GAD.

\subsection{Associations of multiple occupational exposures with MDE and GAD}


All psychosocial work dimensions except workplace violence displayed dose-response associations with MDE and GAD (Figures 1-2). Linear trend tests were all significant. The risk of GAD also increased with the exposure to workplace violence in women. Consequently, there was a significant linear association between the total number of psychosocial work exposures and MDE/GAD in both genders ( $p$ for trend $<.002$ ).

In addition, there was a significant increase in the odds ratios for MDE with the number of physical work exposures in both genders, but the linear association was not significant for GAD. No linear trend was found between the number of working time/hours factors and MDE or GAD.

The results remained unchanged in the sensitivity analyses.

\section{4 | DISCUSSION}

\section{1 | Main findings}

When each occupational factor was studied separately, most psychosocial work factors were found to be associated with MDE and GAD. Furthermore, linear associations between the number of these factors and MDE/GAD were observed, except for workplace violence. Regarding working time/hours, unsocial work days was significantly associated with GAD in women. High biomechanical work exposure, occupational exposures to fumes and dust, and noise for both genders, and toxic and dangerous products in women, were associated with MDE. An increasing risk of MDE with multiple exposure to physical work factors was observed in both genders.

\section{2 | Comparison with the literature}


In our study, MDE and GAD were measured by a standardized diagnostic interview based on DSM-IV criteria. The observed prevalence of MDE and GAD, as well as the differences in prevalence between genders, were consistent with previous estimates in the working population in France (Murcia, Chastang, \& Niedhammer, 2013).

Our results on job demands are in line with literature reviews on common mental disorders (that were mainly symptomatic outcomes) (Netterstrøm et al., 2008; Nieuwenhuijsen et al., 2010; S. Stansfeld \& Candy, 2006; Theorell et al., 2015), and with the few previous studies on depression based on diagnostic interviews (Blackmore et al., 2007; Plaisier et al., 2007; S. A. Stansfeld, Clark, Caldwell, Rodgers, \& Power, 2008; J. Wang \& Patten, 2001; JianLi Wang, 2004). The association of job demands with anxiety disorders has been much less studied and the results remain inconsistent: some rare studies showed that high job demands were either a risk factor (Isabelle Niedhammer, Malard, \& Chastang, 2015; S. A. Stansfeld et al., 2008), or a non-significant factor (Plaisier et al., 2007) or a protective factor (Wieclaw et al., 2008). Our results add to the literature by showing that that various types of job demands, including quantitative demands, cognitive demands and demands for hiding emotions, were associated with MDE or GAD. High emotional demands were previously reported to be associated with MDE (Wieclaw et al., 2008) or GAD (Isabelle Niedhammer et al., 2015). To our knowledge, no previous study has reported an association between cognitive demands and MDE/GAD.

According to some literature reviews, there was moderate to strong evidence of association between low job control and depressive or mental health symptoms (Bonde, 2008; Nieuwenhuijsen et al., 2010; S. Stansfeld \& Candy, 2006; Theorell et al., 2015). Some rare studies showed an association between low job control and clinical depression (Blackmore et al., 2007; J. Wang \& Patten, 2001; JianLi Wang, 2004). Inconclusive results were reported for 
the association of job control with anxiety disorders (Isabelle Niedhammer et al., 2015; Plaisier et al., 2007; Wieclaw et al., 2008). In our study, we were able to explore various components of job control: influence at work, possibilities for development, and degree of freedom, something that has never been done before for diagnostic interview outcomes. Our study is also the first to show that low meaning of work was a risk factor for both MDE and GAD.

Almost all psychosocial factors related to interpersonal relationship and leadership were associated with MDE in our study. The associations found for low social support at work, low role clarity and role conflict are in line with literature reviews based mainly on studies using symptomatic outcomes (Netterstrøm et al., 2008; Nieuwenhuijsen et al., 2010; Schmidt et al., 2014; S. Stansfeld \& Candy, 2006; Theorell et al., 2015) and with results from studies on clinical depression (Blackmore et al., 2007; J. Wang \& Patten, 2001; JianLi Wang, 2004). Low social support and ethical conflict were found to be predictive of GAD in a previous study among French employees (Isabelle Niedhammer et al., 2015). We found significant associations between low role clarity, role conflict and GAD in women. The studies are lacking for all these factors in association with diagnostic interview outcomes, especially GAD.

The associations of job insecurity and changes at work with MDE in our study are consistent with the literature focusing mainly on mental health and depressive symptoms (Fløvik, Knardahl, \& Christensen, 2019; Kim \& von dem Knesebeck, 2016; Rönnblad et al., 2019; S. Stansfeld \& Candy, 2006; Theorell et al., 2015). The studies using diagnostic instruments or on anxiety are missing. Job insecurity was found to be predictive of depression and anxiety in a study among French employees (Isabelle Niedhammer et al., 2015), but no association with anxiety disorders was observed in a study in the Dutch population (Plaisier et al., 2007). 
Previous reviews underlined the associations of workplace bullying and violence with mental health problems, more particularly symptomatic outcomes (Theorell et al., 2015; Verkuil et al., 2015). Some rare studies reported associations between bullying/violence and clinical depression (Gullander et al., 2014; Oenning, Ziegelmann, Goulart, \& Niedhammer, 2018; Rugulies et al., 2012). Our results provide additional information by showing that internal violence may be more strongly associated with MDE and GAD than external violence.

We found almost no association between working time/hours and MDE and GAD in our study. The lack of association for long working hours in our study is consistent with a systematic review based on depressive disorders clinically diagnosed or assessed by a structured interview (Watanabe et al., 2016). The literature is lacking for anxiety. Inconclusive results were reported by literature reviews regarding the association between shift work and mental health outcomes (Lee et al., 2017; Torquati et al., 2019). Two previous studies using diagnostic interviews (Isabelle Niedhammer et al., 2015; Oenning et al., 2018) also found no significant association of night/shift work with depression and anxiety.

Very few studies are available on the associations between physical working conditions and depression or anxiety related outcomes (Theorell et al., 2015). Our findings are in agreement with the results from a Brazilian population-based study showing associations between intense physical activity, exposure to noise and chemicals and clinical depression among women (Oenning et al., 2018). In contrast, there was no association of biomechanical, physical and chemical exposures with MDE and GAD in a previous French study (Isabelle Niedhammer et al., 2015).

Studies on the combined effects of multiple occupational exposures on mental disorders are lacking. Job strain which combines high psychological demands and low job control and effort-reward imbalance that combines high effort and low reward were found to be 
associated with clinical depression (Madsen et al., 2017) and depressive disorders (including symptom scales) (Rugulies et al., 2017). To our knowledge, only one recent study assessed the impact of the psychosocial work environment as a whole (Stauder et al., 2017) and showed an increased prevalence of high stress and burn-out symptoms with multiple exposure to psychosocial work factors. Our study is thus a major contribution to the literature on the topic of multiple occupational exposure in association with depression and anxiety as assessed using diagnostic interview.

\section{3 | Strengths and limitations}

The study was based on a large nationally representative sample of the French working population. The participation rate to the survey $(74 \%)$ and the response rate to the selfadministered questionnaire (94\%) were high. All statistical analyses were performed using weighted data, results could thus be extrapolated to the whole French working population of employees. The analyses were stratified by gender because of differences in the prevalence of $\mathrm{MDE} / \mathrm{GAD}$, occupational exposures and covariates, as well as in the exposure-outcome associations between men and women, following the best practices regarding genderrelated research (I. Niedhammer, Saurel-Cubizolles, Piciotti, \& Bonenfant, 2000). Our study focused on two common mental disorders, MDE and GAD, that were measured by a standardized diagnostic interview and DSM-IV criteria. There was comorbidity between MDE and GAD, as $47.4 \%$ of men and $47.0 \%$ of women having MDE also had GAD and $42.8 \%$ of men and $46.3 \%$ of women having GAD also had MDE, which may explain common and specific occupational risk factors for these two disorders. MDE and GAD were studied with comorbid cases in our analyses, as excluding these cases would have led to a reduced statistical power. Additional analyses performed to study MDE and GAD without comorbid 
cases confirmed the results, although statistical significance was reduced for some associations with GAD among men. The assessment of occupational exposures included a large number of psychosocial work factors, together with factors related to working time/hours and physical work exposures. A major strength of the study was the assessment of multiple exposures to occupational factors that has been greatly understudied. Furthermore, all our analyses were adjusted for covariates that were important factors in association with MDE/GAD. The results of the unadjusted and adjusted models (slightly lower ORs after adjustment) showed that these covariates had a low confounding effect on the associations between occupational factors and MDE/GAD, and underlined the need and interest to adjust for these covariates. Sensitivity analyses were performed and confirmed the results.

Because of the cross-sectional design of our study, no causal or temporal inference can be made. A healthy worker effect may also be assumed and lead to an underestimation of the associations, as employees with MDE/GAD may have changed job or left the labour market because of their occupational exposures. Our assessment of occupational exposures was not based on validated questionnaires. However, the very detailed data collection allowed us to study a wide range of occupational exposures. However, some rare factors may be missing such as organisational injustice (Nieuwenhuijsen et al., 2010; Theorell et al., 2015). As both occupational factors and outcomes were assessed using self-reported data, a reporting bias may be suspected. Nevertheless, this bias may be small because MDE and GAD were measured by a standardized diagnostic interview.

\section{4 | Conclusion}


This study showed that a wide variety of occupational exposures were associated with clinical depression and anxiety. It also underlined the increase in risk of depression/anxiety with multiple occupational exposures. More studies are needed to confirm these associations and the cumulative effects of occupational exposures on these outcomes. More attention should be given to multiple exposures at the workplace, in order to improve mental health among working populations. 


\section{REFERENCES}

Birnbaum, H. G., Kessler, R. C., Kelley, D., Ben-Hamadi, R., Joish, V. N., \& Greenberg, P. E. (2010). Employer burden of mild, moderate, and severe major depressive disorder : Mental health services utilization and costs, and work performance. Depression and Anxiety, 27(1), 78-89. https://doi.org/10.1002/da.20580

Blackmore, E. R., Stansfeld, S. A., Weller, I., Munce, S., Zagorski, B. M., \& Stewart, D. E. (2007). Major depressive episodes and work stress : Results from a national population survey. American Journal of Public Health, 97(11), 2088-2093. https://doi.org/10.2105/AJPH.2006.104406

Bonde, J. P. E. (2008). Psychosocial factors at work and risk of depression : A systematic review of the epidemiological evidence. Occupational and Environmental Medicine, 65(7), 438-445. https://doi.org/10.1136/oem.2007.038430

EU-OSHA. (2014). EU-OSHA - European Agency for Safety and Health at Work, Calculating the cost of work-related stress and psychosocial risks. Luxembourg.

Fløvik, L., Knardahl, S., \& Christensen, J. O. (2019). Organizational change and employee mental health : A prospective multilevel study of the associations between organizational changes and clinically relevant mental distress. Scandinavian Journal of Work, Environment \& Health, 45(2), 134-145. https://doi.org/10.5271/sjweh.3777

Gullander, M., Hogh, A., Hansen, Å., Persson, R., Rugulies, R., Kolstad, H., ... Bonde, J. (2014). Exposure to Workplace Bullying and Risk of Depression. Journal of Occupational and Environmental Medicine, 56(12), 1258-1265.

https://doi.org/10.1097/JOM.0000000000000339

Gutiérrez-Rojas, L., Porras-Segovia, A., Dunne, H., Andrade-González, N., \& Cervilla, J. A.

(2020). Prevalence and correlates of major depressive disorder: a systematic review 
[published online ahead of print, 2020 Aug 3]. Braz J Psychiatr, S1516-

44462020005024201. https://doi.org/10.1590/1516-4446-2020-0650

Harvey, S. B., Modini, M., Joyce, S., Milligan-Saville, J. S., Tan, L., Mykletun, A., ... Mitchell, P. B. (2017). Can work make you mentally ill? A systematic meta-review of work-related risk factors for common mental health problems. Occupational and Environmental Medicine, 74(4), 301-310. https://doi.org/10.1136/oemed-2016-104015

Kim, T. J., \& von dem Knesebeck, O. (2016). Perceived job insecurity, unemployment and depressive symptoms : A systematic review and meta-analysis of prospective observational studies. International Archives of Occupational and Environmental Health, 89(4), 561-573. https://doi.org/10.1007/s00420-015-1107-1

Knudsen, A. K., Harvey, S. B., Mykletun, A., \& Øverland, S. (2013). Common mental disorders and long-term sickness absence in a general working population. The Hordaland Health Study. Acta Psychiatrica Scandinavica, 127(4), 287-297.

https://doi.org/10.1111/j.1600-0447.2012.01902.x

Kristensen, T. S., Hannerz, H., Høgh, A., \& Borg, V. (2005). The Copenhagen Psychosocial Questionnaire-A tool for the assessment and improvement of the psychosocial work environment. Scandinavian Journal of Work, Environment \& Health, 31(6), 438-449.

Lecrubier, Y., Sheehan, D., Weiller, E., Amorim, P., Bonora, I., Harnett Sheehan, K., ... Dunbar, G. (1997). The Mini International Neuropsychiatric Interview (MINI). A short diagnostic structured interview : Reliability and validity according to the CIDI. European Psychiatry, 12(5), 224-231. https://doi.org/10.1016/S0924-9338(97)832968 
Lee, A., Myung, S. K., Cho, J. J., Jung, Y. J., Yoon, J. L., \& Kim, M. Y. (2017). Night Shift Work and Risk of Depression : Meta-analysis of Observational Studies. Journal of Korean Medical Science, 32(7), 1091-1096. https://doi.org/10.3346/jkms.2017.32.7.1091

Madsen, I. E. H., Nyberg, S. T., Magnusson Hanson, L. L., Ferrie, J. E., Ahola, K., Alfredsson, L., ... IPD-Work Consortium. (2017). Job strain as a risk factor for clinical depression : Systematic review and meta-analysis with additional individual participant data. Psychological Medicine, 47(8), 1342-1356.

https://doi.org/10.1017/S003329171600355X

Michael, T., Zetsche, U., \& Margraf, J. (2007). Epidemiology of anxiety disorders. Psychiatry, 6(4), 136-142. https://doi.org/10.1016/j.mppsy.2007.01.007

Murcia, M., Chastang, J.-F., \& Niedhammer, I. (2013). Psychosocial work factors, major depressive and generalised anxiety disorders : Results from the French national SIP study. Journal of Affective Disorders, 146(3), 319-327. https://doi.org/10.1016/j.jad.2012.09.014

Netterstrøm, B., Conrad, N., Bech, P., Fink, P., Olsen, O., Rugulies, R., \& Stansfeld, S. (2008). The relation between work-related psychosocial factors and the development of depression. Epidemiologic Reviews, 30, 118-132. https://doi.org/10.1093/epirev/mxn004

Niedhammer, I., Saurel-Cubizolles, M. J., Piciotti, M., \& Bonenfant, S. (2000). How is sex considered in recent epidemiological publications on occupational risks? Occupational and Environmental Medicine, 57(8), 521-527. https://doi.org/10.1136/oem.57.8.521

Niedhammer, Isabelle, Malard, L., \& Chastang, J.-F. (2015). Occupational factors and subsequent major depressive and generalized anxiety disorders in the prospective 
French national SIP study. BMC Public Health, 15, 200.

https://doi.org/10.1186/s12889-015-1559-y

Nieuwenhuijsen, K., Bruinvels, D., \& Frings-Dresen, M. (2010). Psychosocial work environment and stress-related disorders, a systematic review. Occupational Medicine (Oxford, England), 60(4), 277-286. https://doi.org/10.1093/occmed/kqq081

Oenning, N. S. X., Ziegelmann, P. K., Goulart, B. N. G. de, \& Niedhammer, I. (2018). Occupational factors associated with major depressive disorder : A Brazilian population-based study. Journal of Affective Disorders, 240, 48-56. https://doi.org/10.1016/j.jad.2018.07.022

Pejtersen, J. H., Kristensen, T. S., Borg, V., \& Bjorner, J. B. (2010). The second version of the Copenhagen Psychosocial Questionnaire. Scandinavian Journal of Public Health, 38(3 Suppl), 8-24. https://doi.org/10.1177/1403494809349858

Plaisier, I., de Bruijn, J. G. M., de Graaf, R., ten Have, M., Beekman, A. T. F., \& Penninx, B. W. J. H. (2007). The contribution of working conditions and social support to the onset of depressive and anxiety disorders among male and female employees. Social Science \& Medicine (1982), 64(2), 401-410. https://doi.org/10.1016/j.socscimed.2006.09.008 Rönnblad, T., Grönholm, E., Jonsson, J., Koranyi, I., Orellana, C., Kreshpaj, B., ... Bodin, T. (2019). Precarious employment and mental health : A systematic review and metaanalysis of longitudinal studies. Scandinavian Journal of Work, Environment \& Health, 45(5), 429-443. https://doi.org/10.5271/sjweh.3797

Rugulies, R., Aust, B., \& Madsen, I. E. (2017). Effort-reward imbalance at work and risk of depressive disorders. A systematic review and meta-analysis of prospective cohort studies. Scandinavian Journal of Work, Environment \& Health, 43(4), 294-306. https://doi.org/10.5271/sjweh.3632 
Rugulies, R., Madsen, I. E. H., Hjarsbech, P. U., Hogh, A., Borg, V., Carneiro, I. G., \& Aust, B. (2012). Bullying at work and onset of a major depressive episode among Danish female eldercare workers. Scandinavian Journal of Work, Environment \& Health, 38(3), 218-227. https://doi.org/10.5271/sjweh.3278

Schmidt, S., Roesler, U., Kusserow, T., \& Rau, R. (2014). Uncertainty in the workplace: Examining role ambiguity and role conflict, and their link to depression-a metaanalysis. European Journal of Work and Organizational Psychology, 23(1), 91-106. https://doi.org/10.1080/1359432X.2012.711523

Sheehan, D., Lecrubier, Y., Harnett Sheehan, K., Janavs, J., Weiller, E., Keskiner, A., ... Dunbar, G. (1997). The validity of the Mini International Neuropsychiatric Interview (MINI) according to the SCID-P and its reliability. European Psychiatry, 12(5), 232-241. https://doi.org/10.1016/S0924-9338(97)83297-X

Sheehan, D. V., Lecrubier, Y., Sheehan, K. H., Amorim, P., Janavs, J., Weiller, E., ... Dunbar, G. C. (1998). The Mini-International Neuropsychiatric Interview (M.I.N.I.) : The development and validation of a structured diagnostic psychiatric interview for DSMIV and ICD-10. The Journal of Clinical Psychiatry, 59 Suppl 20, 22-33;quiz 34-57.

Stansfeld, S. A., Clark, C., Caldwell, T., Rodgers, B., \& Power, C. (2008). Psychosocial work characteristics and anxiety and depressive disorders in midlife : The effects of prior psychological distress. Occupational and Environmental Medicine, 65(9), 634-642. https://doi.org/10.1136/oem.2007.036640

Stansfeld, S., \& Candy, B. (2006). Psychosocial work environment and mental health-A meta-analytic review. Scandinavian Journal of Work, Environment \& Health, 32(6), 443-462. 
Stauder, A., Nistor, K., Zakor, T., Szabó, A., Nistor, A., Ádám, S., \& Konkolÿ Thege, B. (2017). Quantifying Multiple Work-Related Psychosocial Risk Factors : Proposal for a Composite Indicator Based on the COPSOQ II. International Journal of Behavioral Medicine, 24(6), 915-926. https://doi.org/10.1007/s12529-017-9651-6

Theorell, T., Hammarström, A., Aronsson, G., Träskman Bendz, L., Grape, T., Hogstedt, C., . Hall, C. (2015). A systematic review including meta-analysis of work environment and depressive symptoms. BMC Public Health, 15, 738. https://doi.org/10.1186/s12889015-1954-4

Torquati, L., Mielke, G. I., Brown, W. J., Burton, N. W., \& Kolbe-Alexander, T. L. (2019). Shift Work and Poor Mental Health : A Meta-Analysis of Longitudinal Studies. American Journal of Public Health, e1-e8. https://doi.org/10.2105/AJPH.2019.305278

Verkuil, B., Atasayi, S., \& Molendijk, M. L. (2015). Workplace Bullying and Mental Health : A Meta-Analysis on Cross-Sectional and Longitudinal Data. PloS One, 10(8), e0135225. https://doi.org/10.1371/journal.pone.0135225

Virtanen, M., Jokela, M., Madsen, I. E., Magnusson Hanson, L. L., Lallukka, T., Nyberg, S. T., ... Kivimäki, M. (2018). Long working hours and depressive symptoms : Systematic review and meta-analysis of published studies and unpublished individual participant data. Scandinavian Journal of Work, Environment \& Health, 44(3), 239-250. https://doi.org/10.5271/sjweh.3712

Wang, J., \& Patten, S. B. (2001). Perceived work stress and major depression in the Canadian employed population, 20-49 years old. Journal of Occupational Health Psychology, 6(4), 283-289. https://doi.org/10.1037//1076-8998.6.4.283 
Wang, JianLi. (2004). Perceived work stress and major depressive episodes in a population of employed Canadians over 18 years old. The Journal of Nervous and Mental Disease, 192(2), 160-163. https://doi.org/10.1097/01.nmd.0000110242.97744.bc

Watanabe, K., Imamura, K., \& Kawakami, N. (2016). Working hours and the onset of depressive disorder : A systematic review and meta-analysis. Occupational and Environmental Medicine, 73(12), 877-884. https://doi.org/10.1136/oemed-2016103845

Wedegaertner, F., Arnhold-Kerri, S., Sittaro, N.-A., Bleich, S., Geyer, S., \& Lee, W. E. (2013). Depression- and anxiety-related sick leave and the risk of permanent disability and mortality in the working population in Germany : A cohort study. BMC Public Health, 13, 145. https://doi.org/10.1186/1471-2458-13-145

Wieclaw, J., Agerbo, E., Mortensen, P. B., Burr, H., Tuchsen, F., \& Bonde, J. P. (2008). Psychosocial working conditions and the risk of depression and anxiety disorders in the Danish workforce. BMC Public Health, 8, 280. https://doi.org/10.1186/1471$2458-8-280$

World Health Organization. (2017). World Health Organization. Depression and other common mental disorders : Global health estimates. Geneva. 


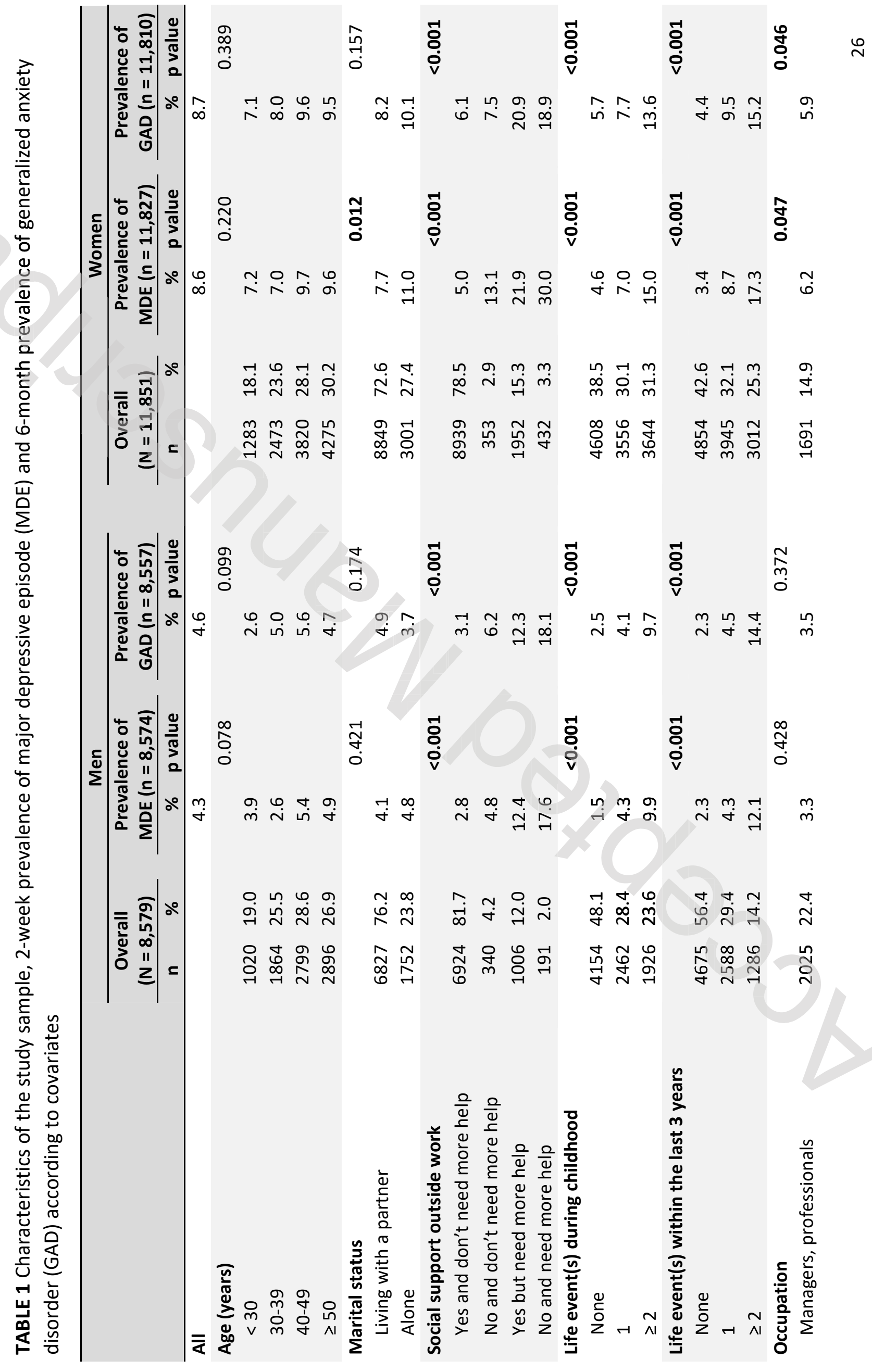




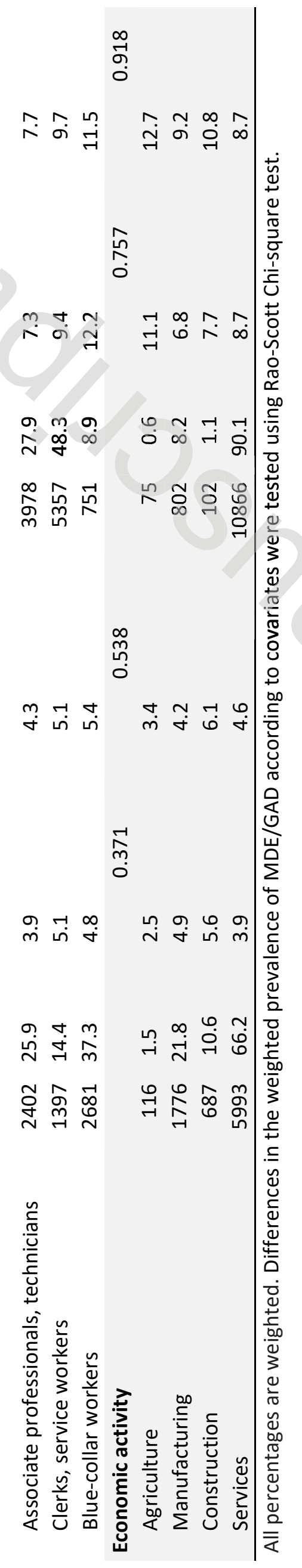




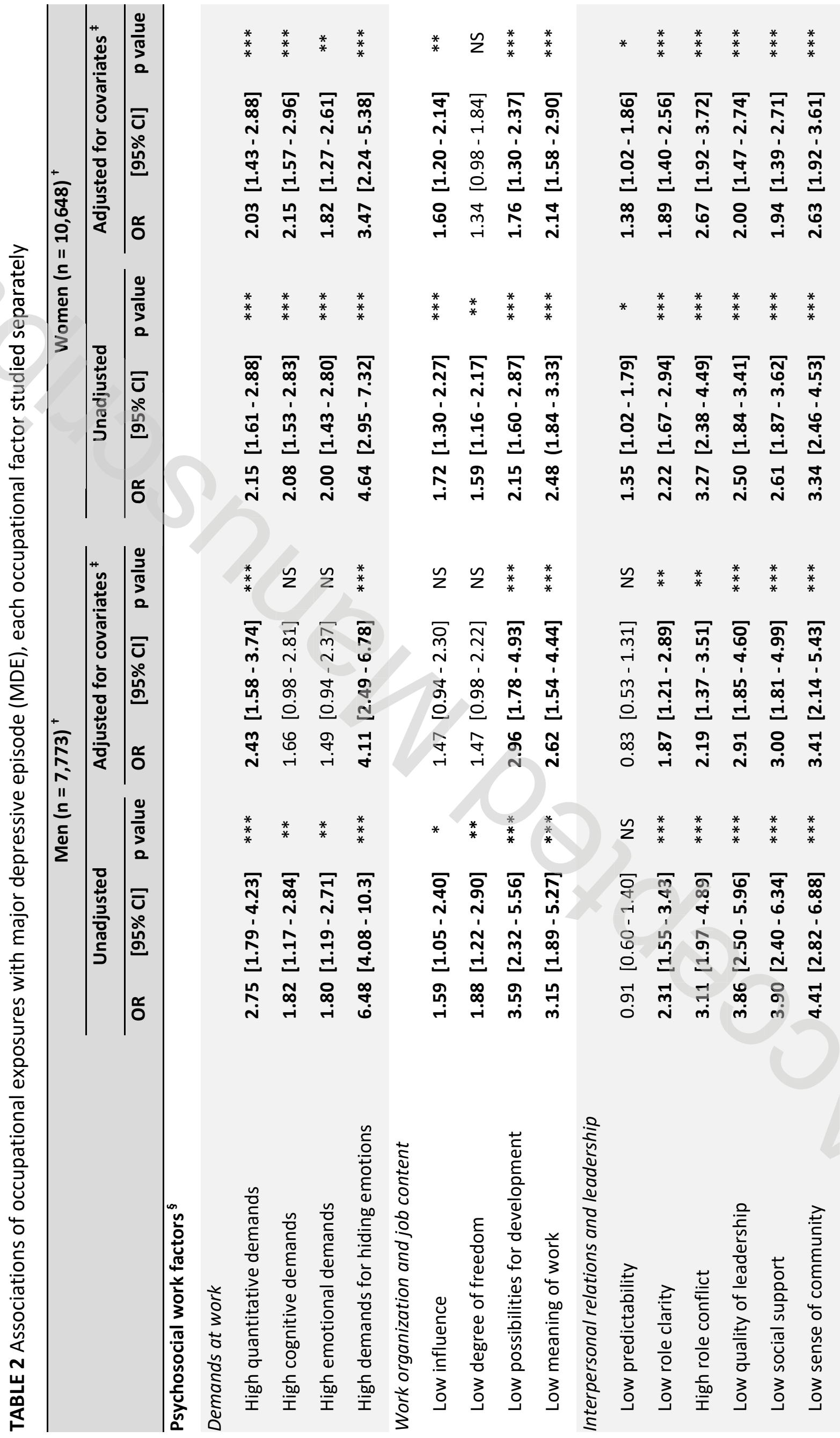




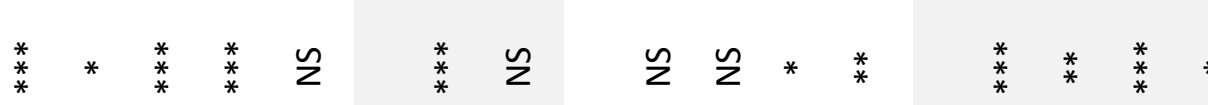

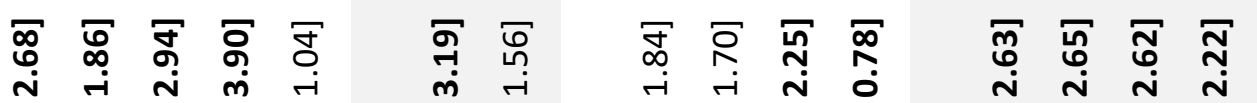

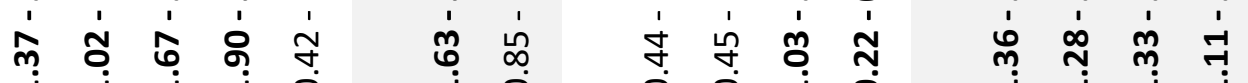

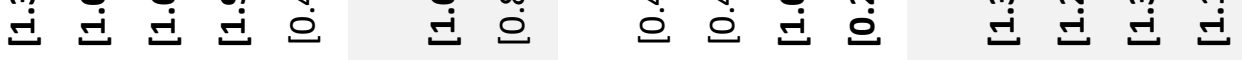

స

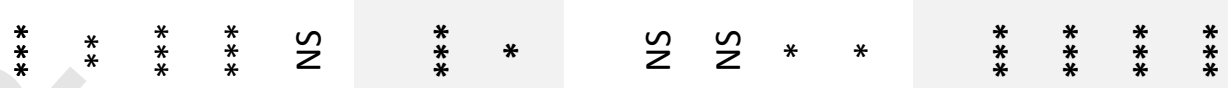

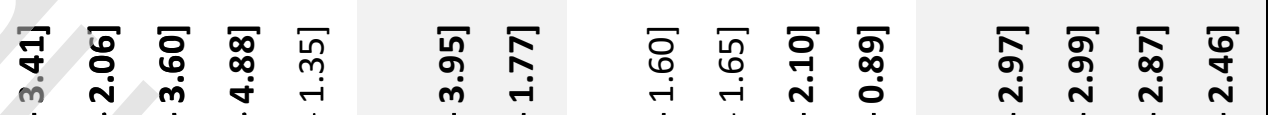

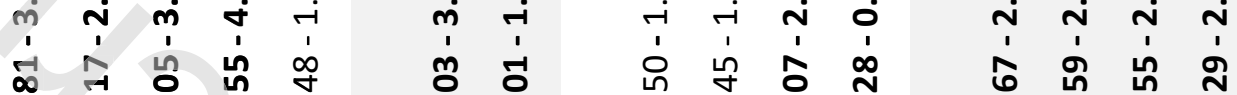

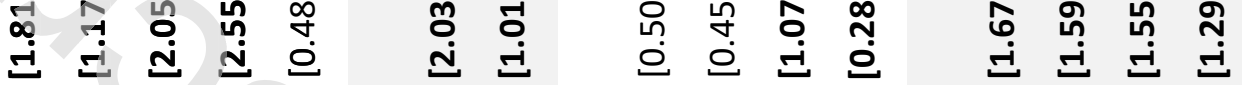

胥苦 N N

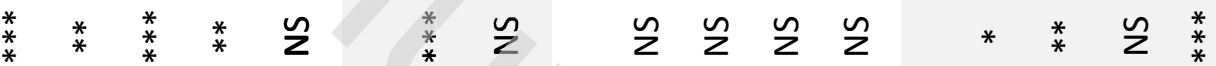

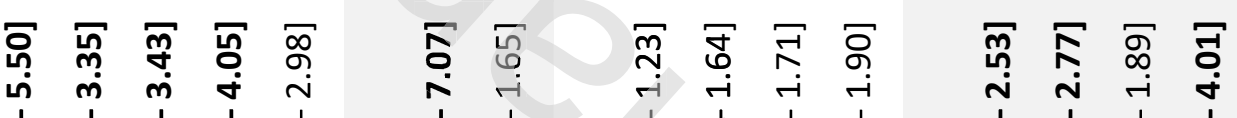

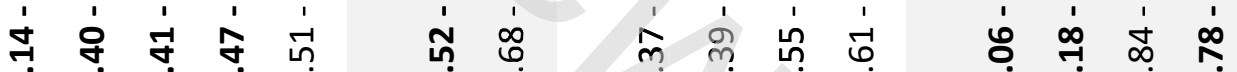

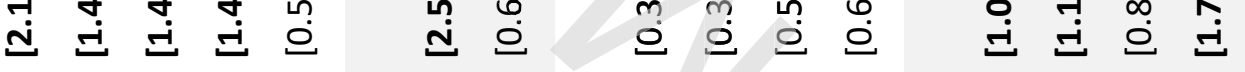

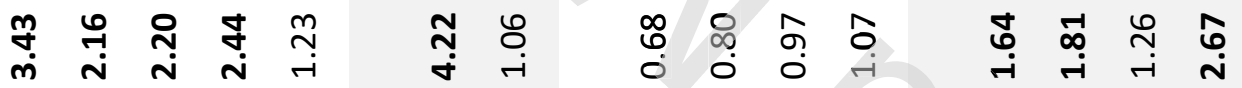

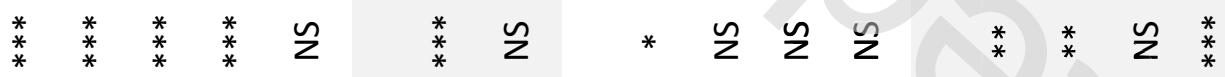

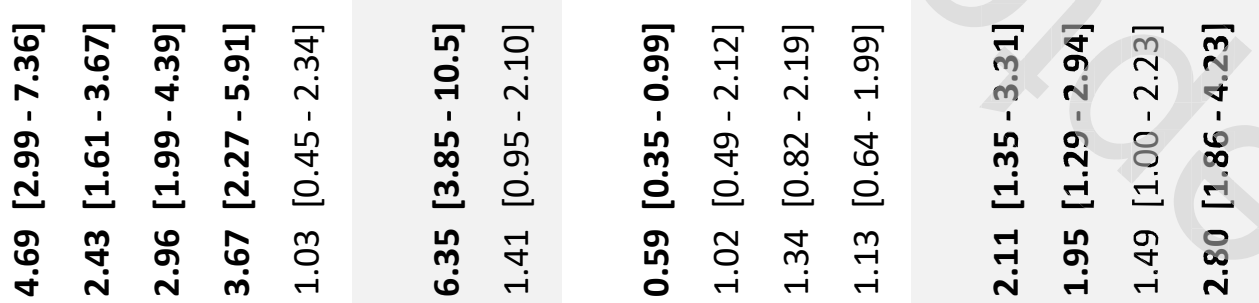

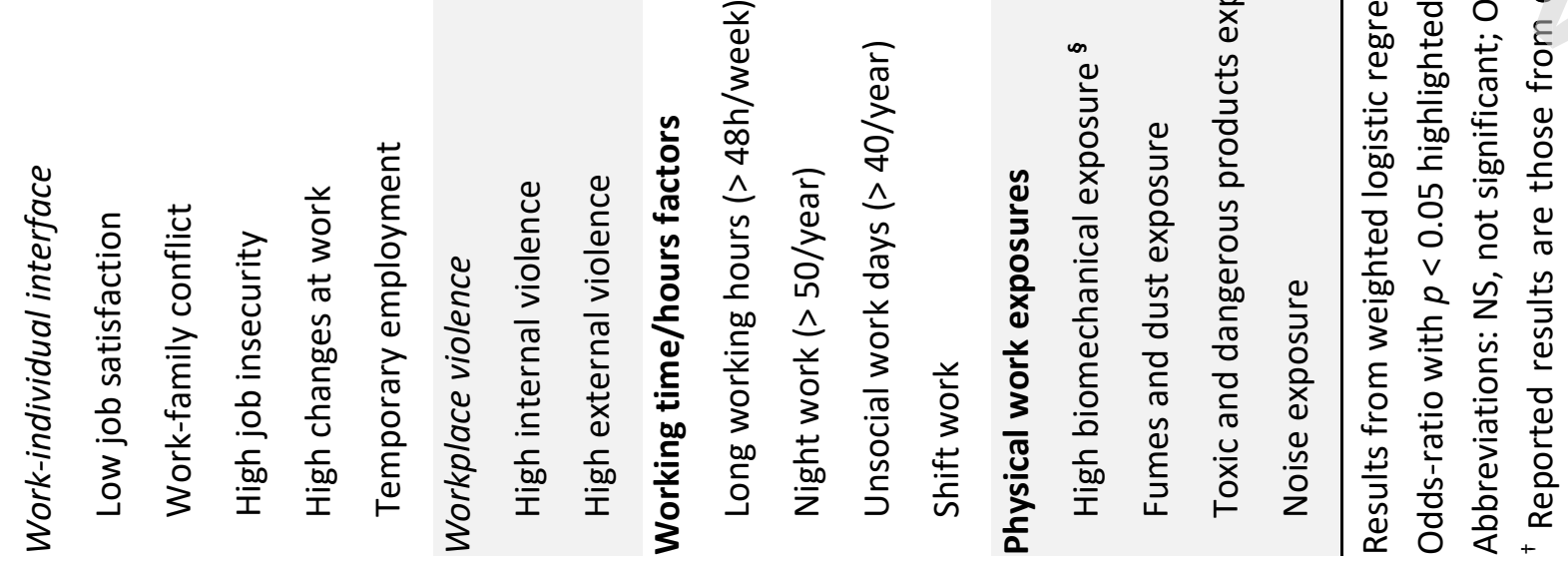




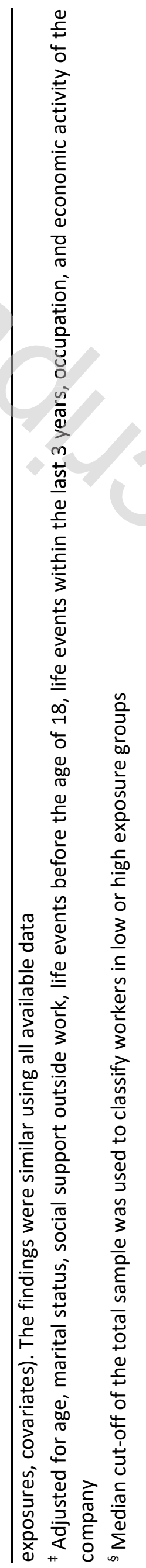

m 


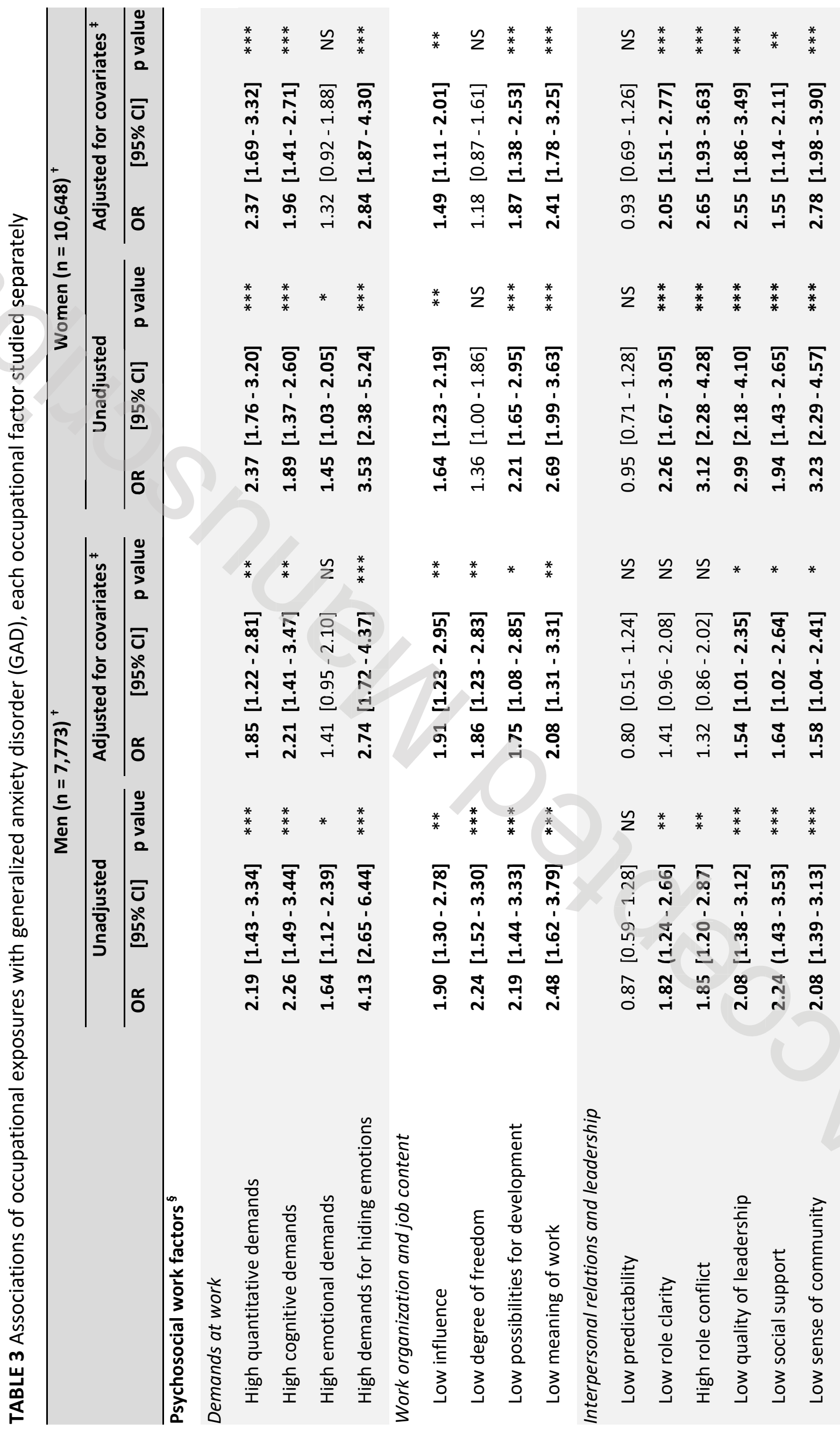




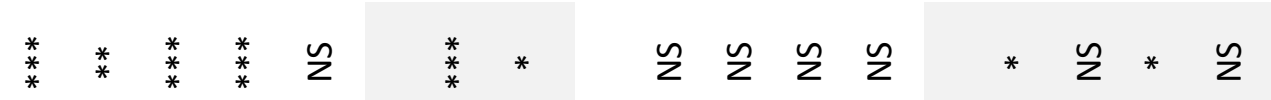

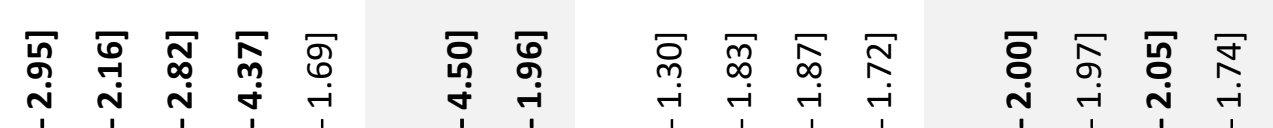

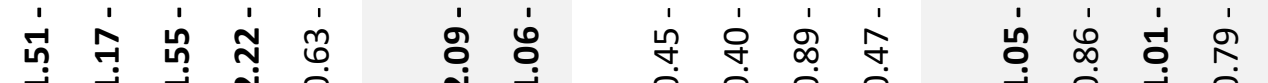

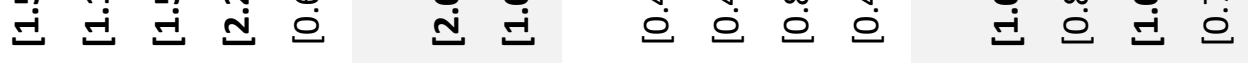

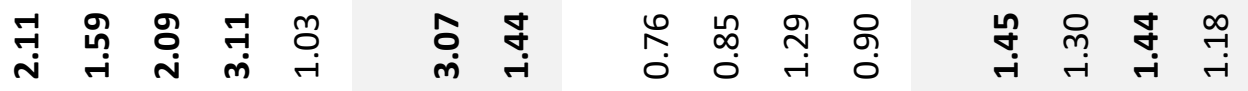

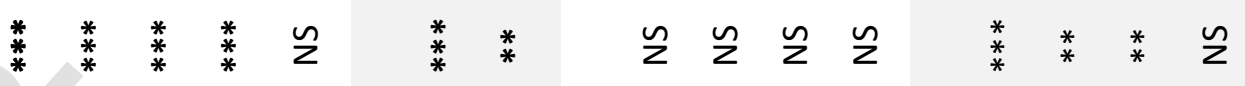

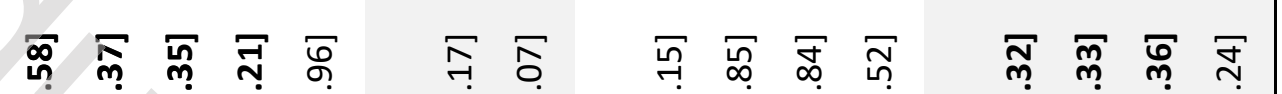

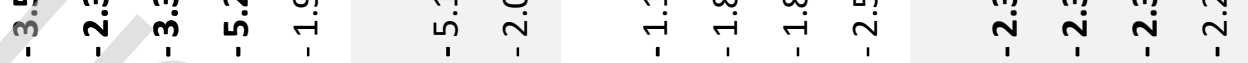

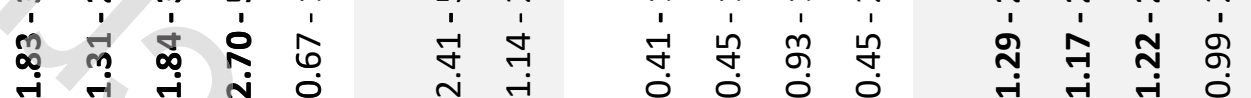

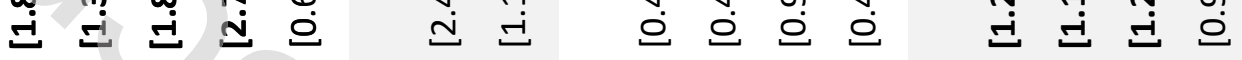

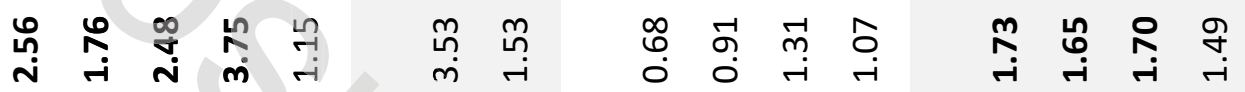

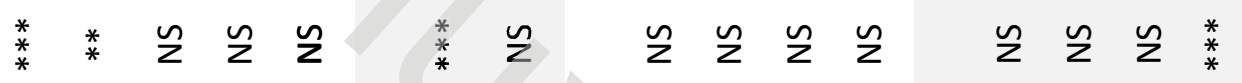

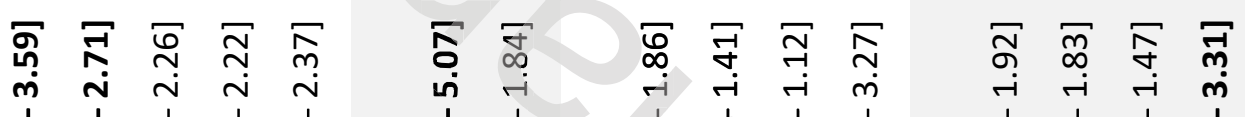

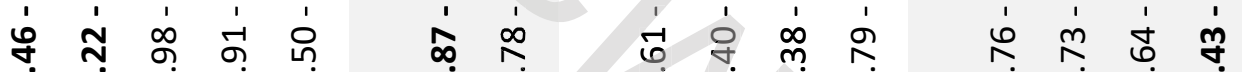

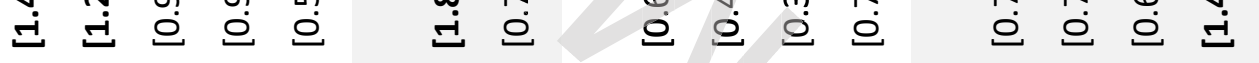

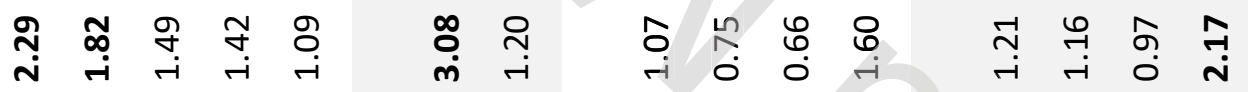

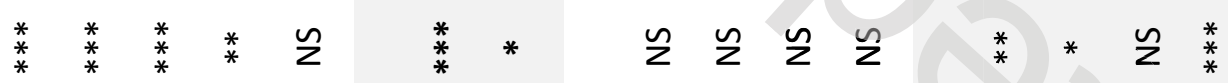

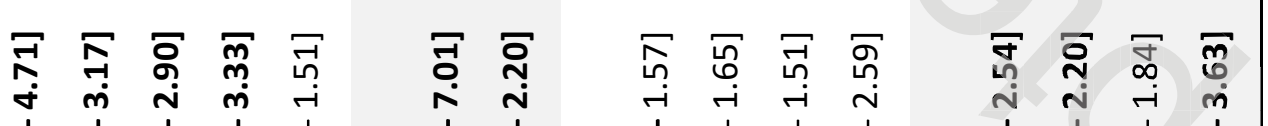

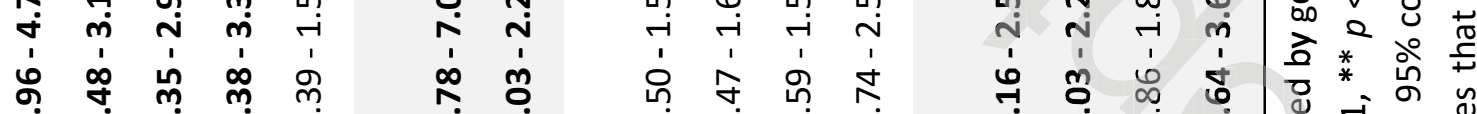

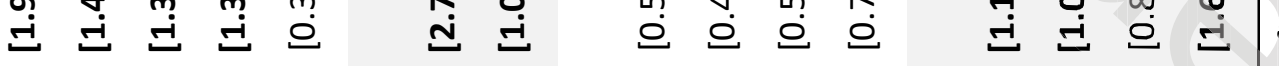

芦

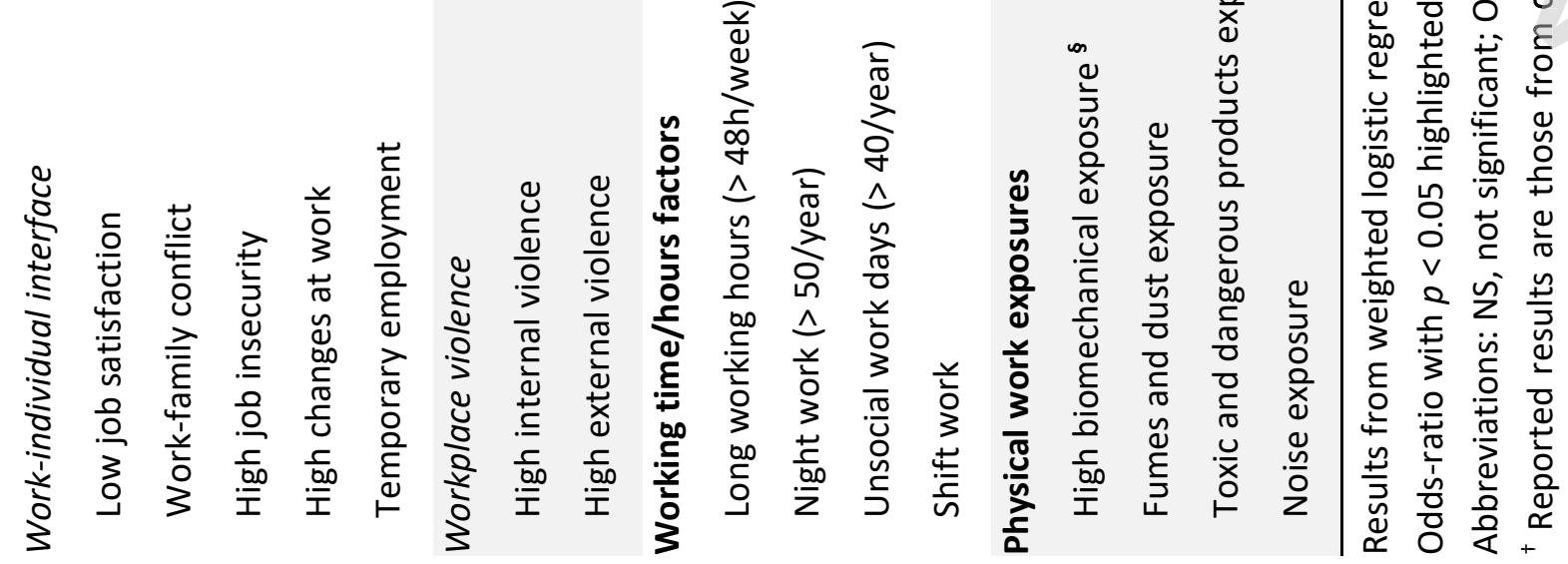




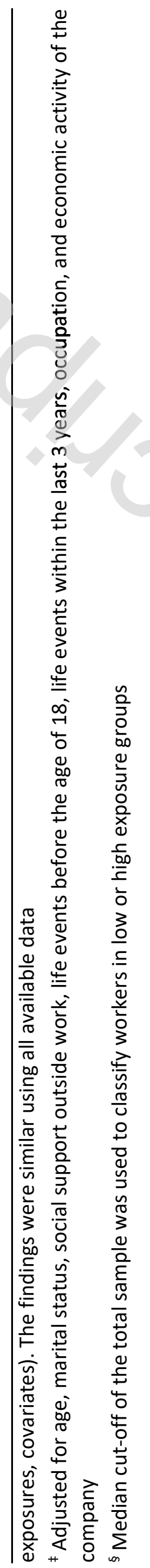

$m$ 
FIGURE 1 Odds-ratio (OR) and 95\% confidence interval (Cl) for major depressive episode (MDE) according to the number of occupational factors, after adjustment for covariates

Number of occupational factors:

\% $0-1$ (ref.) $\square 2 \square 3 \square 4 \square 5 \square 6$

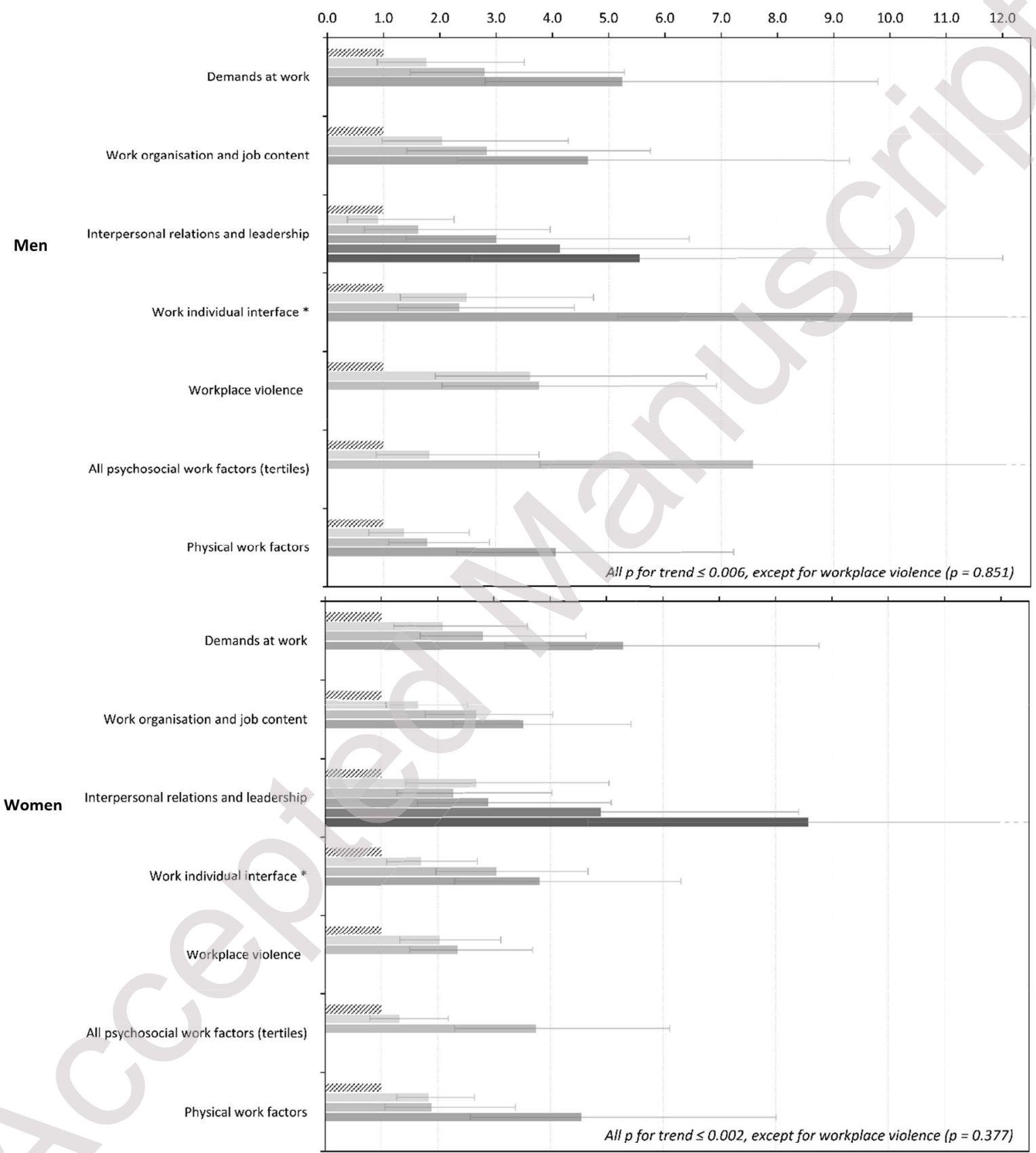

* Employees with 4 and 5 occupational factors were grouped, because of the low number of participants with 5 factors 
FIGURE 2 Odds-ratio (OR) and 95\% confidence interval (CI) for generalized anxiety disorder (GAD) according to the number of occupational factors, after adjustment for covariates

Number of occupational factors:

\%0-1 (ref.) $\square 2 \square 3 \square 4 \square 5 \square 6$

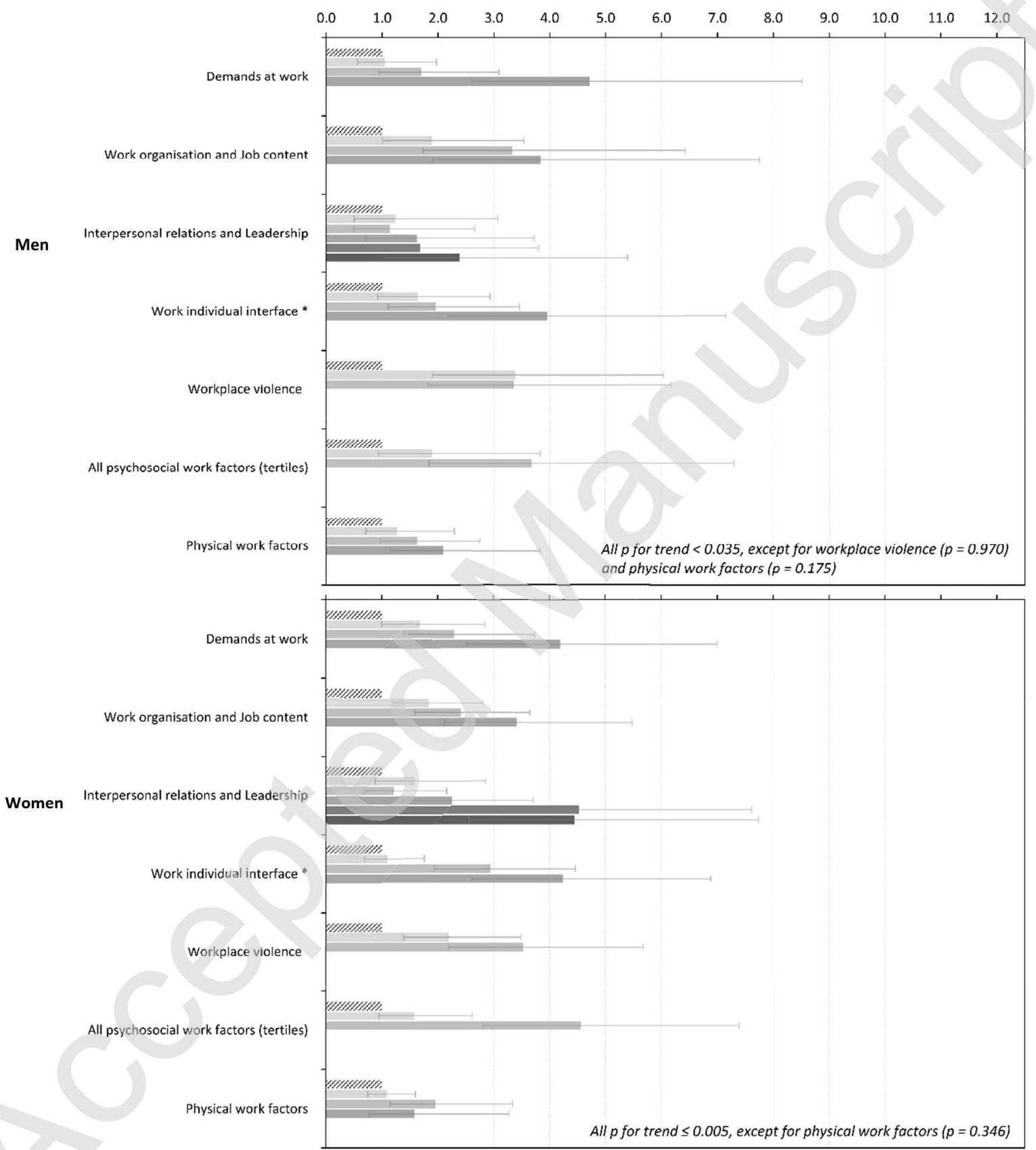

* Employees with 4 and 5 occupational factors were grouped, because of the low number of participants with 5 factors 